\title{
Safe Placement of Ommaya Reservoirs in Thrombocytopenic Patients: One Institutions Experience
}

\author{
Kimberly Major ${ }^{1}$, Abraham Schlauderaff ${ }^{1}$, Amalia Brawley ${ }^{2}$, David E. Hale ${ }^{1}$, Elias Rizk ${ }^{1}$ \\ 1. Neurosurgery, Penn State Milton S. Hershey Medical Center, Hershey, USA 2. Neurosurgery, Penn State College of \\ Medicine, Penn State Milton S. Hershey Medical Center, Hershey, USA
}

Corresponding author: Abraham Schlauderaff, aschlauderaff@pennstatehealth.psu.edu

\section{Abstract \\ Objective}

The purpose of this study was to assess the risk of hemorrhagic complications in thrombocytopenic patients after Ommaya reservoir placement.

\section{Methods}

Between 2009 and 2017, 192 patients were identified on the National Neoplastic Meningitis Registry and had undergone Ommaya reservoir placement for intrathecal chemotherapy. A retrospective chart review was performed to collect the preoperative and postoperative platelet levels, whether or not the patient received any transfusion of platelets, neurological exams, and whether a postoperative head CT was obtained. Using generally accepted recommendations, a platelet level less than $100,000 / \mu \mathrm{L}$ was considered clinically significant and used as our threshold for thrombocytopenia.

\section{Results}

Seven patients (3.6\%) were identified as thrombocytopenic in our patient population with platelet counts ranging from 54,000 to $99,000 / \mu \mathrm{L}$. Primary diagnoses for the seven patients included leukemia, prostate cancer, primary brain cancer (four patients), and lung cancer (non-small-cell lung carcinoma). One patient received platelet transfusions preoperatively. Three patients had a routine head CT obtained postoperatively with no abnormal findings noted. There were no changes in the neurological exam noted in all of the patients included in this study. No clinically significant hemorrhages were identified in our patients.

\section{Conclusions}

From our single institutional experience, we found that thrombocytopenia is fairly uncommon, found in only $3.6 \%$ of our patients undergoing placement of Ommaya reservoirs. We did not encounter any increased risks of postoperative hemorrhage in studied thrombocytopenic patients.

Received 06/27/2019

Review began 07/24/2019

Review ended 07/30/2019

Published 07/31/2019

(c) Copyright 2019

Major et al. This is an open access article

distributed under the terms of the Creative Commons Attribution License CC-BY 3.0., which permits unrestricted use, distribution, and reproduction in any medium, provided the original author and source are credited.
Categories: Neurosurgery

Keywords: ommaya, thrombocytopenia, stereotactic, hemorrhage

\section{Introduction}

Dr. Ayub Ommaya, a pioneering neurosurgeon, originally started placing subcutaneous cerebrospinal fluid reservoirs in 1962 and soon thereafter published his results [1]. This procedure consists of passing a ventricular catheter into the lateral ventricle through a burr hole. The catheter is then attached to a subcutaneous reservoir, which may be accessed via subsequent needle punctures. Since its conception, the Ommaya reservoir has developed widespread usage for treatment of various forms of intracranial malignancies. There are potential, well-described complications associated with the Ommaya reservoir, including aseptic meningitis, catheter-related infection, catheter malplacement, wound dehiscence, and leakage of cerebrospinal fluid [2,3]. However, there is scant literature describing intraparenchymal hemorrhage risk associated with placement of the Ommaya reservoir. A National Surgical Quality Improvement Program analysis by Dasenbrock et al. found moderate $(100,000-124,000 / \mu \mathrm{L})$ and severe $(75,000-99,000 / \mu \mathrm{L})$ thrombocytopenia were associated with mortality and reoperation after craniotomy for tumor [4]. Field et al. described their experience of intracerebral hemorrhage after stereotactic biopsy in five hundred patients, which showed the only statistically significant factor was the degree to which the platelet count fell below 150,000/ $\mu \mathrm{L}$ [5]. Kennedy et al. reported a hemorrhagic complication rate of $6.4 \%$ (seven out of 109 patients) after stereotactic catheter placement for Ommaya reservoirs, with one patient experiencing preoperative thrombocytopenia [6].

Ommaya reservoirs are commonly placed for chronic administration of intrathecal chemotherapy in various 
disease states such as neoplastic meningitis or central nervous system (CNS) lymphoma. Not uncommonly, patients may have concurrent systemic disease processes including disorders of myelopoiesis, prohibiting safe placement of Ommaya reservoirs. Thrombocytopenia is often considered a contraindication to neurosurgical procedures, and the current expert opinion is that a platelet count threshold of $100,000 / \mu \mathrm{L}$ should be used to decrease the risk of hemorrhagic complications [7]. However, the concept of a "safe" platelet count lacks evidence-based recommendations and demonstrates great variability between patients even with the same disorder. Current hematologic guidelines suggest an increased risk of surgical bleeding with platelet counts less than $50,000 / \mu \mathrm{L}$ in major surgery and invasive procedures such as lumbar puncture, liver biopsy, endoscopy with biopsy, and placement of central venous catheter [8]. For high-risk procedures operations to critical sites, eye surgery, and neurosurgery, it is suggested that a platelet count of less than $100,000 / \mu \mathrm{L}$ be obtained before proceeding with surgery [8]. In the present study, we describe our single institution's experience of safely placing Ommaya reservoirs in thrombocytopenic patients.

\section{Materials And Methods}

Since 2011, all Penn State Health patients that had Ommaya reservoirs placed for neoplastic meningitis were included in the National Neoplastic Meningitis Registry. A retrospective review of all patients in the registry was performed to collect the following data: preoperative and postoperative platelet levels, whether or not the patient received any transfusion of platelets, change in the neurological exam, and whether a postoperative head CT was obtained. The discrepancy between pre- and postoperative neurological exams was queried to ascertain a clinically relevant hemorrhage. Cranial imaging, e.g. head CT, when available, was also reviewed to assess for intra-parenchymal hemorrhage presence and severity. Using generally accepted recommendations, we determined that a platelet level less than $100,000 / \mu \mathrm{L}$ was clinically significant and thus was used as our threshold for thrombocytopenia. Patient data was de-identified and stored using Research Electronic Data Capture (REDCap).

\section{Results}

There were a total of 192 patients entered in the National Neoplastic Meningitis Registry at the time this study took place. Surgeries were performed between 2009 and 2017. Seven patients (3.6\%) were identified to have a platelet count less than 100,000/ $\mu \mathrm{L}$ (ranging 54,000-99,000/ $\mathrm{L}$ ). Primary diagnoses for the seven patients included leukemia, prostate cancer, primary brain cancer (four patients), and lung cancer (nonsmall-cell lung carcinoma). One patient received platelet transfusions preoperatively to correct a level of $45,000 / \mu \mathrm{L}$ which was deemed too low by the primary surgeon. Three patients had a routine head CT obtained postoperatively with no abnormal findings noted. There were no changes in the neurological exam noted in all of the patients included in this study (Table 1 ).

\begin{tabular}{|c|c|c|c|c|c|}
\hline Patient & Preop Platelet Level (K/uL) & Postop Platelet Level (K/uL) & Transfusion Given & Neurological Change & СT Performed \\
\hline 1 & 99 & 97 & No & No & No \\
\hline 2 & 89 & 97 & Yes & No & Yes - Normal \\
\hline 3 & 84 & 68 & No & No & Yes - Normal \\
\hline 4 & 94 & 85 & No & No & Yes - Normal \\
\hline 5 & 85 & 114 & No & No & No \\
\hline 6 & 77 & 102 & No & No & No \\
\hline 7 & 54 & 121 & No & No & No \\
\hline
\end{tabular}

TABLE 1: Breakdown of surgical patients' platelet counts, transfusion, neurological and CT status

\section{Discussion}

There is limited data in the literature regarding safe passage through the brain parenchyma in patients with thrombocytopenia. Dasenbrock et al. previously found that the strongest predictor of any cranial reoperation after craniotomy for tumor was preoperative thrombocytopenia [4]. The results of our study indicate that there is no increased risk of postoperative hemorrhage with preoperative thrombocytopenia during placement of Ommaya catheters, contrary to Field et al. findings in stereotactic biopsies [5]. These findings may be applicable to other forms of targeted stereotactic procedures such as ventricular shunt placement, and further research is needed in this area. This study is limited by its relatively small sample size, the lack of a control group and its retrospective nature. Furthermore, variability in stereotactic equipment used among different neurosurgery teams, patient demographics and comorbidities, and surgical technical skills make it difficult to generalize our results to all candidates for Ommaya reservoirs. 


\section{Conclusions}

From our single institutional experience, we found that thrombocytopenia is uncommon, found in $3.6 \%$ of our patients undergoing placement of Ommaya reservoirs. We did not encounter any clinically relevant hemorrhage in our thrombocytopenic patients. We conclude that the benefits of Ommaya reservoir placement outweigh the risks associated with thrombocytopenia in the neoplastic meningitis population. As always, close monitoring of platelet counts pre and postoperatively is imperative to the safety and efficacy of neurosurgical procedures in thrombocytopenic patients.

\section{Additional Information \\ Disclosures}

Human subjects: Consent was obtained by all participants in this study. Animal subjects: All authors have confirmed that this study did not involve animal subjects or tissue. Conflicts of interest: In compliance with the ICMJE uniform disclosure form, all authors declare the following: Payment/services info: All authors have declared that no financial support was received from any organization for the submitted work. Financial relationships: All authors have declared that they have no financial relationships at present or within the previous three years with any organizations that might have an interest in the submitted work. Other relationships: All authors have declared that there are no other relationships or activities that could appear to have influenced the submitted work.

\section{References}

1. Ratcheson RA, Ommaya AK: Experience with the subcutaneous cerebrospinal-fluid reservoir. Preliminary report of 60 cases. N Engl J Med. 1968, 279:1025-1031. 10.1056/NEJM196811072791904

2. Gerber NU, Müller A, Bellut D, Bozinov O, Berger C, Grotzer MA: Ventricular catheter systems with subcutaneous reservoirs (Ommaya reservoirs) in pediatric patients with brain tumors: infections and other complications. Neuropediatrics. 2015, 46:401-409. 10.1055/s-0035-1565271

3. Chamberlain MC, Kormanik PA, Barba D : Complications associated with intraventricular chemotherapy in patients with leptomeningeal metastases. J Neurosurg. 1997, 87:694-699. 10.3171/jns.1997.87.5.0694

4. Dasenbrock HH, Devine CA, Liu KX, Gormley WB, Claus EB, Smith TR, Dunn IF: Thrombocytopenia and craniotomy for tumor: a National Surgical Quality Improvement Program analysis. Cancer. 2016, 122:17081717. 10.1002/cncr.29984

5. Field M, Witham TF, Flickinger JC, Kondziolka D, Lunsford LD: Comprehensive assessment of hemorrhage risks and outcomes after stereotactic brain biopsy. J Neurosurg. 2001, 94:545-551. 10.3171/jns.2001.94.4.0545

6. Kennedy BC, Brown LT, Komotar RJ, McKhann GM 2nd : Stereotactic catheter placement for Ommaya reservoirs. J Clin Neurosci. 2016, 27:44-47. 10.1016/j.jocn.2015.11.005

7. Chan KH, Mann KS, Chan TK: The significance of thrombocytopenia in the development of postoperative intracranial hematoma. J Neurosurg. 1989, 71:38-41. 10.3171/jns.1989.71.1.0038

8. Liumbruno GM, Bennardello F, Lattanzio A, Piccoli P, Rossetti G: Recommendations for the transfusion management of patients in the peri-operative period. I. The pre-operative period. Blood Transfus. 2011, 9:19-40. 10.2450/2010.0074-10 